graduate medical education is necessary and would benefit patients.

Recently my partners and I completed a 12 month study in our general practice. This study included a digital rectal examination (with the patient in the left lateral position) of the prostate glands of roughly 500 men. This was part of an attempt to screen all the 850 men aged between 55 and 69 in our practice to try to detect cancer of the prostate gland. ${ }^{2}$ We found digital rectal examination a useless screening investigation. Although we felt competent in using digital rectal examination to confirm a clinical suspicion in patients with symptoms, we were not confident using digital rectal examination to detect important abnormalities of the prostate gland in patients without symptoms

TERRY KEMPLE

Horfield Health Centre,

Bristol BS7 9RR

1 Hennigan TW, Franks PJ, Hocken DB, Allen-Mersh TG. Rectal examination in general practice. Br Med f 1990;301:478-80. (8 September.)

2 Chadwick D, Gillatt DA, Gingell JC, Abrams PH. Screening for carcinoma of the prostate. Br Med $\mathcal{f}$ 1990;301:119-20. (14 July.)

AUTHORS' REPLY, - The term rectal examination describes what every British medical student is taught when learning rectal examination: to inspect the anus and carry out a digital examination of the anal canal and lower rectum. We accept that as with proctoscopy, which is not inspection of the rectum, and rigid sigmoidoscopy, which does not usually visualise the sigmoid colon, the term does not describe what is done. It is, however, the name used in Britain and a competent medical graduate should have no doubt about what is required as well as having the skills to do it. We have made a video, How to do a $P R$, which is available free of charge to any interested doctor who contacts the senior author (TGA-M)

Our purpose was not to set out the indications for rectal examination but to ascertain those applied by the general practitioners we questioned. There was a disquietingly wide variation, and we identified certain factors associated with this, which if corrected would increase the number of rectal examinations done by general practitioners. As Dr Kemple mentions, rectal examination is of little value as a screening test. This should not be confused, however, with its role in patients with symptoms. There are few colorectal surgeons who have not had any experience of advanced rectal cancer that is easily palpable on rectal examination in a patient who has had symptoms for months but has previously been reassured by a general practitioner who did not do a rectal examination.

Rectal examination is one important consideration in the general practitioner's decision about which patients are to be referred to a rectal clinic and about the urgency of referral. No patient with anorectal symptoms should be reassured by his or her general practitioner without undergoing rectal examination.

TOM HENNIGAN

P J FRANKS

Charing Cross and Westminster Medical School,

London W6 8RF

\section{Referral letters and replies from orthopaedic departments}

SIR, - Mr L G H Jacobs and Dr M A Pringle will cause more than a few eyebrows to be raised with their observation that a referral letter marked "urgent" did not significantly reduce the waiting time for outpatients below the mean 23.4 weeks. ${ }^{1}$ Surely this should be denounced, provided that the system was not being abused. Similarly, it has to be indefensible on the part of orthopaedic surgeons not to reply to specific questions by the general practitioner seeking help as seemed to be the case more often than not. Of course it is not stated whether the question was illegible, inappropriate after nearly six months of waiting time, or too vague for comprehension.

Clearly, referral letters need to be explicit and the replies informative. I doubt, however, whether "educational" is the right term, and I wonder if time is ever found to read the very long educational letter. The authors implied that poor referral letters should stimulate orthopaedic surgeons to be more educational in their replies. In the real world, I am afraid, a poor referral letter, especially the "Dear doctor" one, stimulates no more than a poor reply: (For example, Dear Specialist, ?foot, Yours GP; reply: Dear GP, Agree! Yours Hospital Doctor.)

There are many factors surrounding the problem of orthopaedic referrals, one being that in many parts of the country there are only half the number of orthopaedic surgeons per head of population compared with the number in most other parts of western Europe. The point of this letter, however, is to state that the British Orthopaedic Association is most concerned about the education of general practitioners and their rapport with orthopods. In a recent survey of its members the association found that general practitioner referrals were considered to be trivial or unnecessary in up to $40 \%$ of cases, with $17 \%$ being the mean figure. If by better education general practitioners could manage to care for the greater proportion of musculoskeletal ailments this would release orthopaedic surgeons to deal with the more serious and pressing conditions. It might also allow them to spend more time in the operating theatre to start reducing their enormous waiting lists.

The association is currently setting up a working party with representatives of the Royal College of General Practitioners and rheumatologists (through the British League Against Rheumatism) to consider the paramount need for improved education in orthopaedics and rheumatological conditions. There is no doubt that musculoskeletal science and medicine demand a much higher profile in the undergraduate curriculum, as well as in the senior house officer training for general practice and in teaching programmes at postgraduate centres, etc. A competent general practitioner should be able to treat chronic strains like tennis elbow and diagnose such conditions as spondylosis and mechanical back pain with the facility of direct referral to NHS physiotherapists, who are now so highly trained.

In fact I cannot think of anything more cost effective than to implement such changes as soon as possible.

\section{British Orthopaedic Association,}

London WC2A 3PN

1 Jacobs LGH, Pringle MA. Referral letters and replies from orthopaedic departments: opportunities missed. $\mathrm{Br}$ Med $f$ 1990;301:470-3. (8 September.)

\section{Mobility allowance}

SIR,-Dr David Black highlighted the age discrimination in eligibility for assistance from the Independent Living Fund.' The mobility allowance also discriminates against elderly people, and many doctors are failing their patients because they are unaware of the rules regarding claims. There is an absolute bar to claiming, which in almost all cases applies once the patient has reached the age of 65 .

The only people who are likely to see the patients who could be considered for this allowance are general practitioners. A notice in a waiting room is simply not enough as many of these patients by the nature of their condition will not go to a waiting room. As a part time chairman of a social security appeal tribunal, I cannot count the number of disappointed claimants whom we have to tell that they are just too late. I have seen six in three tribunal sessions in just three weeks. When they say that "nobody told me I could claim" I submit that the onus lies on their doctors, and I implore all general practitioners to examine their methods and ensure that somebody in their practice, if not everybody, makes the point to the under $65 \mathrm{~s}$ where applicable.

The claim must be made; whether or not the award is given is entirely up to the medical authorities, which is outside my brief.

ELAINE GOLDMAN

Liverpool L18 3ED

1 Black D. The Independent Living Fund. Br Med $\mathcal{F}$ 1990;301 385. (18-25 August.)

\section{Cycling masks}

SIR,-Cycling masks, as Dr Fiona Godlee rightly points out, are an unproved method in preventive medicine. It is somewhat disturbing, however, to note that in the accompanying photograph the young man is not wearing a crash helmet - a proved method in preventive medicine. While you are campaigning for research into air pollution could you also campaign for the compulsory wearing of crash helmets by cyclists?

Westminster Children's Hospital,

MARTIN C O BAX London SWIP 2NS

I Godlee F. Cycling masks: how effective? Br Med f 1990;301:508 (15 September.)

\section{Drug Points}

\section{Dystonic dysphagia associated with fluspirilene}

Drs Martina Stones, David C Kennie, and JAMES D FultoN (Stirling Royal Infirmary, Stirling) write: Dysphagia in the elderly is associated with considerable morbidity and substantial mortality. Some dysphagias, however, are potentially remediable.

An 89 year old woman was admitted with a one day history of absolute dysphagia. Although her medical history included cerebrovascular disease and dementia, dysphagia was a new symptom. She was taking only fluspirilene $3 \mathrm{mg} /$ week, which she had last received on the day before admission. She had been treated with this drug for two months for intermittent behavioural disturbance. Examination confirmed that she was choking on saliva, that she had evidence of an established left hemiparesis, and that she had no other features suggestive of tardive dyskinesia.

Biochemical and haematological values were normal as was a chest radiograph, and electrocardiography showed initial atrial fibrillation with spontaneous reconversion to sinus rhythm. Endoscopy was performed but showed only gastric atrophy. After she returned to the ward an appreciable improvement in her swallowing was observed, which unfortunately then rapidly deteriorated back to the previous level. As it was considered that the premedication for endoscopy (glycopyrronium $2 \mathrm{mg}$ intramuscularly) might be of chronological importance, a diagnosis of acute dystonic dysphagia was considered. Correspondingly, benztropine $2 \mathrm{mg}$ was given intravenously, which resulted in a further, sustained improvement in her dysphagia. She was discharged and two months later there had been no recurrence. This idiosyncratic dystonic reaction has been reported to the Committee on Safety of Medicines and is 
the first recorded association of dysphagia with fluspirilene, although four episodes of dystonia and one dyskinetic reaction have occurred since 1975.

Acute dystonic reactions are well recognised with neuroleptic drugs,' but acute dystonic dysphagia has only recently been reported; NewtonJohn described the condition in two patients, the causal drug probably being metoclopramide, although prochlorperazine was implicated in one. ${ }^{2}$ The treatment of choice for acute dystonic reactions is an anticholinergic drug. Persistent dystonia, however, may prove resistant to drugs. The treatment options include anticholinergic drugs, levodopa, benzodiazepines, carbamazepine, tetrabenazine, and even phenothiazines or butyrophenones. ${ }^{3}$ Also, with the recognition of the therapeutic use of botulinum toxin $\mathrm{A}$ in spasmodic dysphonia $^{+}$this may offer an alternative acceptable solution to the problem of dystonic dysphagia when withdrawal of the causal neuroleptic is not clinically feasible.

1 Lader MH. Neuroleptics and abnormal movements. Br Med $\mathcal{F}$ 1982;285:463-4

2 Newton-John H. Acute upper airway obstruction due to supraglottic dystonia induced by a neuroleptic. Br Med $\mathcal{Y}$ 1988;297:964-5.

3 Anonymous. The management of dystonias. [Editorial.] Lancet $1985 ; \mathrm{i}: 321-2$

4 Marsden CD, Quinn NP. The dystonias. Br Med f 1990;300: $139-44$.

\section{Captopril and systemic lupus erythematosus syndrome}

Drs C Sieber, E Grimm, and F Follath (Division of Clinical Pharmacology, University Hospital, Basle, Switzerland) write: Lupoid skin reactions ${ }^{2}$ and haematological side effects ${ }^{3.5}$ induced by captopril have been recorded, but systemic lupus erythematosus syndrome induced by captopril is thought to be rare and of uncertain origin, and no conclusive case has been described.$^{67}$ We report on a patient taking captopril who developed signs of systemic lupus erythematosus syndrome.

A 53 year old man who had had insulin dependent diabetes mellitus since the age of 20 and had proved diabetic microangiopathy and macroangiopathy began treatment for hypertension and congestive heart failure with captopril $(25 \mathrm{mg}$ twice daily) in March 1987. He was already taking frusemide ( $40 \mathrm{mg}$ twice daily), isosorbide dinitrate (40 $\mathrm{mg}$ twice daily), and digoxin ( $0 \cdot 125 \mathrm{mg}$ daily). In September 1987 he presented with relapsing fever and bronchitis, which was treated with doxycycline ( $100 \mathrm{mg}$ daily) without any effect. In February 1988 his dose of captopril was increased to $125 \mathrm{mg}$ daily. Six weeks later the patient complained of arthralgias, fever, and malaise. At this time and subsequently all tests for rheumatoid factors gave negative results, including a test for antibodies to DNA. On admission to hospital in June 1988 the patient was in poor general health and showed, in addition to the symptoms described above, bilateral pleural effusions and a pericardial rub. There was also laboratory evidence for hepatopathy, with increased activity of transaminases.

After infections and other inflammatory agents that could have produced his symptoms had been excluded captopril was stopped. The concomitant drugs remained unchanged. He improved rapidly within five days, the pleural effusions regressed, and signs of pericarditis disappeared. His $\mathrm{Creactive}$ protein concentration, which was raised on ad mission at $7 \cdot 7 \mathrm{~g} / \mathrm{l}$ (normal $<0.5 \mathrm{~g} / \mathrm{l}$ ), fell to $2.7 \mathrm{~g} / \mathrm{l}$ one week later and to a normal value three months later. Simultaneously the increased activities of liver enzymes returned to normal. After he stopped captopril no signs of recurrence were observed.

In view of previous evidence of lupoid skin and haematological changes induced by captopril, the clinical history of this patient, who rapidly improved after stopping this angiotensin converting enzyme inhibitor, is suggestive of a drug induced systemic lupus erythematosus syndrome, although there were no antibodies to DNA-a common finding in drug induced lupus. ${ }^{8}$

1 Patri P, Nigro A, Rebora A. Lupus erythematosus-like eruption from captopril Acta Derm Venereol 1985;65:447-8.

2 Schmidt RE, Lange C. Lupus erythematodes durch captopril. Z Rheumatol 1982;41:182.

3 Brummelen P, Willemze R, Ran WD, et al. Captopril-associated agranulocytosis. Lancet $1980 ; \mathrm{i}: 150$.

4 Elijovisch F, Krakoff LR. Captopril associated granulocytopenia in hypertension after renal transplantation. Lancet 1980;i:927.

5 Shindo K, Matsuya F, Ura T, et al. Captopril-associated granulocytopenia in hypertension after renal transplantation. Clin Nephrol 1984;22:314-6.

6 Kale SA. Drug-induced systemic lupus erythematosus: differentiating it from the real thing. Postgrad Med 1985;77: 231-42.

7 Hughes GRV. Recent developments in drug-associated systemic lupus erythematosus. Adverse Drug Reactions Bulletin 1987; 123:460-3.

8 Hughes GRV. Hypotensive agents, beta-blockers, and druginduced lupus. $\mathrm{Br} M e d$ f 1982;284:1358-9.

\section{Inhibitors of hydroxymethylglutaryl coenzyme A reductase for treating hypercholesterolaemia}

Drs Jacques D Barth, Olga A E Kruisbrink, and ANNELIES L VAN DiJK (Department of Cardiology, Radboud University Hospital Nijmegen, Nijmegen, The Netherlands) write The introduction of the hydroxymethylglutary coenzyme A reductase inhibitors heralded a new era in treating hypercholesterolaemia; they effectively lower lipid concentrations with few side effects. ${ }^{12}$ Their effect on the metabolism of the central nervous system, however, has been insufficiently investigated as the function of the central nervous system is lipid dependent. Schaefer indicated that lovastatin, but not pravastatin, may cross the blood-brain barrier and cause sleep disturbances, indicating that a lipophilic inhibito may be less desirable. ${ }^{3}$ Transient insomnia has been reported with lovastatin, ${ }^{145}$ and we therefore investigated the prevalence of these side effects with the related drug simvastatin in men with hypercholesterolaemia and symptoms of coronary artery disease.

Thirty men with coronary artery disease (who had had a myocardial infarction or coronary artery bypass grafting) were assessed by two dietitian primarily interested in dietary counselling. Patients were randomised in pairs to receive either simvastatin $(20 \mathrm{mg} /$ day) or colestipol ( $15 \mathrm{~g} /$ day). None of the patients had ever taken any other lipid lowering drugs. Duration and patterns of sleep were assessed by questionnaire. Patients were asked if they had ever experienced sleep problems, what time they went to bed to sleep, how they had slept the previous night, and when they had woken up.

None of the patients had previously complained of sleep problems. Patients taking simvastatin slept significantly less $(\mathrm{p}<0.01)$ than the matched controls taking colestipol (table). The main complaint of those who slept less was early awakening. Four of the patients taking simvastatin $(p<0 \cdot 01)$ had repeated sleep interruptions. Neither the cardiological characteristics at baseline nor age (colestipol group: mean age 48, range 28-57; simvastatin group: $46,23-56$ ) were significantly different between the two groups.

Simvastatin seems to have undesirable side effects. Not only did insomnia persist for longer in patients taking this drug than in those taking

Mean (range) duration of sleep in men taking lipid lowering drugs

\begin{tabular}{|c|c|c|c|}
\hline $\begin{array}{l}\text { Duration of } \\
\text { treatment }\end{array}$ & $\begin{array}{c}\text { Simvastatin } \\
(\mathbf{n}=15)\end{array}$ & $\begin{array}{c}\text { Colestipol } \\
(n=15)\end{array}$ & $\mathrm{p}$ Value \\
\hline $\begin{array}{l}\text { Baseline } \\
3 \text { Months } \\
12 \text { Months }\end{array}$ & $\begin{array}{l}8 \mathrm{~h} 16 \mathrm{~min}(7 \mathrm{~h} 15 \mathrm{~min}-9 \mathrm{~h} 20 \mathrm{~min}) \\
7 \mathrm{~h} 12 \mathrm{~min}(6 \mathrm{~h} 15 \mathrm{~min}-8 \mathrm{~h} 40 \mathrm{~min}) \\
7 \mathrm{~h} 15 \mathrm{~min}(6 \mathrm{~h} 20 \mathrm{~min}-8 \mathrm{~h} 35 \mathrm{~min})\end{array}$ & $\begin{array}{l}8 \text { h } 7 \mathrm{~min}(7 \text { h } 20 \mathrm{~min}-9 \text { h } 15 \mathrm{~min}) \\
8 \text { h } 9 \mathrm{~min}(7 \mathrm{~h} 15 \mathrm{~min}-9 \text { h } 5 \mathrm{~min}) \\
8 \text { h } 3 \mathrm{~min}(7 \mathrm{~h} 20 \mathrm{~min}-9 \text { h } 10 \mathrm{~min})\end{array}$ & $\begin{array}{l}\text { NS } \\
<0.01 \\
<0.01\end{array}$ \\
\hline
\end{tabular}

colestipol but repeated sleep interruptions also occurred. The same reduction in cholesterol concentrations was obtained with both groups, suggesting that the reduction in cholesterol was not causing this effect. Although this was a small study and extrapolation should be done with care, simvastatin may have side effects related to its lipophilic character. Special attention should be directed to complaints of sleep disturbances.

I Hoeg JM, Brewer HB Jr. 3-Hydroxy-3-methylglutarylcenzyme A reductase inhibitors in the treatment of hypercholesterolemia. FAMA 1987;258:3532-6.

Lovastatin Study Group III. A multicenter comparison of ovastatin and cholestyramine therapy for severe primary hypercholesterolemia. FAMA 1988;260:359-66.

Schaefer EJ. HMG-CoA reductase inhibitors for hypercholesterolemia. N Engl f Med 1988;319:1222-3.

Sabra R. Topics in clinical pharmacology: lovastatin. $A m \mathcal{F}$ Med Sci 1988;296:426-8.

Dulces MN, Beeley L, eds. Side effects of drugs annual 12 . Amsterdam: Elsevier, 1988:379.

\section{Potentiation of action of warfarin by itraconazole}

Drs John Yeh, Shiu-Ching Soo, and ChrisTOPHER SUMmerton and Miss Christine RICHARDSON (Addenbrooke's Hospital, Cambridge CB2 2QQ) write: We report a case of enhanced action of warfarin associated with oral administration of itraconazole, a new triazole antifungal drug

A 61 year old woman was established on long term treatment with warfarin because of recurrent pulmonary embolism. The warfarin dose had been stable for the past 12 months at $5 \mathrm{mg}$ daily. She was also taking ipratropium bromide, salbutamol, and budesonide inhalers for asthma; quinine sulphate for nocturnal leg cramps; and omeprazole for intractable dyspepsia. All drugs had remained unchanged for over a year.

At a routine chest clinic review itraconazole $200 \mathrm{mg}$ twice daily was started for oral candidiasi induced by inhaled steroids. Four days later she presented to her general practitioner with generalised bruising and recurrent nose bleeds. An international normalised ratio greater than 8 was noted. Warfarin and itraconazole were stopped, but her other drugs remained unchanged. The following day she was admitted as a medical emergency with intractable bleeding and increased generalised bruising. Cardiovascular signs were stable and no other physical signs of disease were found. Her international normalised ratio remained greater than 8 . Her haemoglobin concentration was $107 \mathrm{~g} / \mathrm{l}$. White cell and platelet counts were normal. Values for plasma electrolytes and urea, liver function tests, and serum calcium and phosphate were all normal, as was her fibrinogen concentration.

She was treated with fresh frozen plasma. The bleeding stopped and did not recur. Her international normalised ratio returned to 2.4 over the course of two days, at which point warfarin was started. She was subsequently restabilised at her previous dose.

Itraconazole probably potentiated the effect of warfarin. Fluconazole, also a triazole antifungal drug, is known to enhance the effects of warfarin (Pfizer, personal communication). In premarketing studies itraconazole was not shown to affect the protein binding of warfarin (technical brochure on Sporanox, April 1989, Janssen). The mechanism of interaction between itraconazole and warfarin remains unclear. 